ISSN 0103-8478

\title{
Farelo de crambe nas formas in natura ou reduzida em antinutrientes na dieta do jundiá
}

\author{
In natura or reduced antinutrients forms of crambe meal in the silver catfish diet
}

\author{
Alexandra Pretto ${ }^{I^{*}}$ Leila Picolli da Silva ${ }^{\mathrm{I}}$ João Radünz Neto \\ Lucas Mesquita da Costa Nunes ${ }^{I}$ Isadora Liberalesso de Freitas ${ }^{\mathrm{I}}$ \\ Bruno Bianchi Loureiro ${ }^{I}$ Sergio Alves dos Santos ${ }^{I}$
}

\section{RESUMO}

Este estudo avaliou os efeitos da substituição parcial de farinha de peixe e farinha de carne e ossos por farelo de crambe, sobre o crescimento, enzimas digestivas e parâmetros bioquímicos no jundiá (Rhamdia quelen). Este coproduto agroindustrial foi incluído na alimentação de jundiás na forma in natura ou reduzido em antinutrientes, obtido após a aplicação de tratamento químico ao farelo. A inclusão desses ingredientes foi comparada ao tratamento controle (proteína baseada em farinhas de origem animal) durante nove semanas. Crescimento semelhante ao controle foi observado em peixes alimentados com farelo de crambe in natura ou tratado quimicamente na dieta. A inclusão do farelo in natura reduziu a atividade de protease ácida e colesterol plasmático, mas não alterou os parâmetros bioquímicos hepáticos. Menor concentração de glicogênio e glicose no fígado e aumento na aspartato aminotransferase foi encontrada nos peixes alimentados com farelo de crambe tratado, sinalizando uma condição de carência energética. A similar resposta no crescimento, aliada às leves alterações digestivas e metabólicas com o farelo de crambe in natura em relação ao farelo tratado, pode indicar que, no nível de inclusão utilizado, este ingrediente não necessita de um processo prévio para redução de antinutrientes.

Palavras-chave: fonte proteica vegetal, farinhas de origem animal, Rhamdia quelen, crescimento, metabolismo.

\section{ABSTRACT}

This study evaluated the effects of partial replacement of fish meal and meat and bone meal by plant based meal from the biofuel production chain on growth, digestive enzymes and biochemical parameters in silver catfish, Rhamdia quelen. This agro-byproduct was included in the silver catfish feed as an in natura byproduct or in the reduced antinutrients form, obtained after applying chemical treatment to meal. The inclusion of these ingredients was compared to the control treatment (protein based in animal meal) during nine weeks. Growth similar to the control was observed in fish fed with in nature or treated chemically crambe meal in the diet. Inclusion of in natura crambe meal reduced acid protease activity and plasma cholesterol, but did not alter hepatic biochemical parameters. Lower glycogen and glucose concentration in the liver and increase in aspartate aminotransferase were found in fish fed treated crambe meal, signaling an energy deficiency condition. The similar growth response coupled to slight metabolic and digestive changes with in nature crambe meal in relation to the treated meal may indicate that in the inclusion level used this ingredient does not require prior reduction of antinutrients.

Key words: vegetable protein, animal meal, Rhamdia quelen, growth, metabolism.

\section{INTRODUÇÃO}

Mundialmente, observa-se uma tendência de reduzir a inclusão de farinha e óleo de peixe na alimentação de organismos aquáticos, seja pelo elevado custo, disponibilidade ou competição pelo uso com outras espécies. Nesse caso, a substituição vem sendo feita por outras fontes de proteína animal ou vegetal (YANG et al., 2004; CABRAL et al., 2011). As farinhas de origem animal, apesar do elevado teor proteico, apresentam qualidade variável, dependendo do processamento e matériaprima utilizada (YANG et al., 2004). Já, as fontes de proteína vegetal apresentam algumas características que podem favorecer o seu uso como composição constante, disponibilidade e preço.

No Brasil, a utilização de fontes de proteína alternativa para alimentação de peixes tem aumentado concomitantemente à exploração de

\footnotetext{
'Departamento de Zootecnia, Universidade Federal de Santa Maria (UFSM), 97105-900, Santa Maria, RS, Brasil. E-mail: ale.pretto@yahoo.com.br. *Autor para correspondência. 
matérias-primas para produção de biocombustíveis, já que os coprodutos gerados por esta cadeia podem ser aplicados também nesta área, mediante a avaliação de suas características nutricionais. Um exemplo é o farelo de crambe, cujo teor proteico pode ultrapassar $40 \%$, caracterizando-o como um ingrediente potencial. Esse coproduto resulta após a extração do óleo do crambe (Crambe abyssinica), uma cultura promissora utilizada no País para produção de biodiesel (PITOL et al., 2010).

No entanto, as principais limitações ao uso de ingredientes vegetais como fontes de proteína para peixes referem-se às moléculas antinutricionais presentes que podem afetar o crescimento e a disponibilidade de nutrientes. A retirada desses compostos, através de via térmica, química ou enzimática, pode melhorar o valor nutritivo e o aproveitamento do alimento (KROGDAHL et al., 2010) por espécies como o jundiá (Rhamdia quelen), um peixe nativo com elevada aceitação comercial e potencial de produção (SALHI et al., 2004). Assim, o objetivo deste estudo foi avaliar a resposta de juvenis de jundiá à alimentação com dietas contendo farelo de crambe, através do estudo de indicadores de crescimento, atividade de enzimas digestivas e parâmetros metabólicos.

\section{MATERIAL E MÉTODOS}

Neste estudo, foram utilizados 153 juvenis de jundiá $(22 \pm 0,46 \mathrm{~g}$ e $13 \pm 0,10 \mathrm{~cm})$ obtidos da Estação Experimental de Piscicultura em Cruz Alta, Rio Grande do Sul, Brasil. Os animais foram distribuídos aleatoriamente em nove unidades experimentais (17 peixes em cada tanque com capacidade de $125 \mathrm{~L}$ de água) em um sistema de recirculação de água com dois filtros biológicos, contendo pedra britada e controle da temperatura da água através de duas resistências elétricas $(1.000 \mathrm{~W})$. No período de aclimatação de uma semana, os peixes receberam ração peletizada (32\% proteína bruta) confeccionada no laboratório.

O farelo tratado foi obtido após aplicação sequencial de soluções ácida (mistura de ácido sulfúrico concentrado e água até pH 1,0) e alcoolica (etanol comercial $92,8^{\circ}$ ) e mantido sob agitação durante uma hora. A mistura resultante em cada uma dessas etapas foi filtrada com peneiras (100 e $25 \mu \mathrm{m})$ para separar a parte líquida da sólida. No meio líquido, as frações de proteína dissolvidas foram concentradas através de mudanças no pH da solução (elevação à pH 9,0 com $\mathrm{NaOH} 1 \mathrm{~N}$ e redução à 4,5 com $\mathrm{HCl} 1 \mathrm{~N}$ ). A fração sólida do farelo e a fração proteica concentrada foram secas em estufa $\left(60^{\circ} \mathrm{C}-24\right.$ horas $)$ e combinadas para compor o farelo detoxificado. Esse farelo apresentou menor teor de compostos fenólicos $(-41 \%)$, taninos $(-32 \%)$ e ácido fítico $(-47 \%)$, menos proteína bruta $(-21 \%)$, gordura (-20\%), cálcio (-47\%) e fósforo (-37\%) e mais FDN (15\%) (Tabela 1). Com isso, o delineamento experimental utilizado foi o inteiramente casualizado com três tratamentos e três repetições, quais sejam: CrIN - farelo de crambe in natura; CrT - farelo de crambe tratado quimicamente e CON (controle), com a base proteica composta por farinha de carne e ossos e de peixe (Tabela 2). Os ingredientes utilizados nas formulações foram previamente analisados em relação à composição centesimal, cálcio e fósforo (PRETTO, 2013). O farelo de crambe foi incluído para substituir $20 \%$ da proteína animal e, quando necessário, foram suplementados os aminoácidos lisina e metionina. Para confecção das rações, os ingredientes moídos foram misturados, adicionados de óleo de soja e água (50\% do peso dos ingredientes secos) e as misturas peletizadas em moedor de carne. As rações foram secas em estufa de circulação de ar forçado $\left(50^{\circ} \mathrm{C}-24\right.$ horas $)$ e armazenadas a $-18^{\circ} \mathrm{C}$ até o uso. Os peixes foram alimentados com as rações experimentais $(2-3 \%$ da biomassa de cada tanque, dividida em três refeições diárias - 9, 13 e 17 horas) durante nove semanas. A quantidade de alimento foi ajustada a cada três semanas pela pesagem individual dos animais. Diariamente, os tanques foram limpos através de sifonagem ( 8 e $15 \mathrm{~h} 30 \mathrm{~min}$ ), renovando aproximadamente $10 \%$ da água de cada tanque.

A qualidade da água de criação foi monitorada diariamente para temperatura $\left(21,42 \pm 0,88^{\circ} \mathrm{C}\right)$ e semanalmente analisado oxigênio dissolvido $\left(6,02 \pm 0,71 \mathrm{mg} \mathrm{\textrm {L } ^ { - 1 }}\right) \quad$ (oxímetro $\mathrm{YSI}^{\circledR}$,

Tabela 1 - Nutrientes e antinutrientes analisados no farelo de crambe in natura e tratado quimicamente.

\begin{tabular}{lll}
\hline Parâmetro & Farelo in natura & $\begin{array}{c}\text { Farelo tratado } \\
\text { quimicamente }\end{array}$ \\
\hline Proteína bruta (\%) & $38,19 \pm 0,51$ & $30,13 \pm 0,59^{*}$ \\
Gordura (\%) & $5,98 \pm 0,58$ & $4,79 \pm 0,08^{*}$ \\
Cálcio (\%) & $0,57 \pm 0,09$ & $0,29 \pm 0,02^{*}$ \\
Fósforo (\%) & $0,75 \pm 0,04$ & $0,47 \pm 0,01^{*}$ \\
FDN (\%) & $31,04 \pm 0,43$ & $36,34 \pm 0,34^{*}$ \\
Fenóis totais $(\%)$ & $0,98 \pm 0,08$ & $0,58 \pm 0,03^{*}$ \\
Taninos totais $(\%)$ & $0,66 \pm 0,09$ & $0,45 \pm 0,04^{*}$ \\
Ácido fítico (\%) & $2,26 \pm 0,01$ & $1,19 \pm 0,11^{*}$ \\
\hline
\end{tabular}

Dados $(n=3)$ expressos em $100 \%$ de matéria seca. *Indica diferença entre a forma in natura e tratada do farelo pelo teste $\mathrm{F}$ $(\mathrm{P}<0,05)$. 
Tabela 2 - Formulação, composição centesimal e aminoácidos das dietas experimentais (\%).

\begin{tabular}{|c|c|c|c|}
\hline Ingredientes & $\mathrm{CON}$ & $\mathrm{CrIN}$ & CrT \\
\hline Farinha de peixe & 12,50 & 9,84 & 10,20 \\
\hline Farinha de carne e ossos & 43,50 & 34,80 & 35,50 \\
\hline Farelo de crambe in natura & - & 20,84 & - \\
\hline Farelo de crambe tratado & - & - & 25,00 \\
\hline Farelo de trigo & 12,95 & 6,20 & 7,65 \\
\hline Milho & 16,24 & 10,60 & 5,93 \\
\hline Amido de milho & 2,04 & 5,00 & 7,80 \\
\hline Óleo de soja & 4,00 & 4,15 & 4,89 \\
\hline Sal & 0,50 & 0,50 & 0,50 \\
\hline Fosfato bicálcico & - & 0,65 & - \\
\hline Mistura vitaminas/minerais ${ }^{1}$ & 2,00 & 2,00 & 2,00 \\
\hline Metionina & 0,54 & 0,503 & 0,488 \\
\hline Carbonato de cálcio & - & 0,02 & 0,04 \\
\hline Inerte & 5,73 & 4,89 & - \\
\hline \multicolumn{4}{|l|}{ Composição da dieta } \\
\hline Proteína bruta $^{2}$ & 33,91 & 33,92 & 33,92 \\
\hline Gordura $^{2}$ & 12,45 & 11,86 & 12,50 \\
\hline Cinzas $^{2}$ & 15,14 & 13,48 & 16,00 \\
\hline Fibra em Detergente Neutro ${ }^{2}$ & 6,62 & 9,84 & 12,03 \\
\hline Carboidratos ${ }^{3}$ & 14,16 & 12,39 & 6,83 \\
\hline Energia digestível $^{4}\left(\mathrm{Kcal} \mathrm{kg}^{-1}\right)$ & 3070 & 3077 & 3078 \\
\hline Cálcio $^{2}$ & 2,26 & 2,87 & 3,51 \\
\hline Fósforo total ${ }^{2}$ & 1,37 & 1,72 & 2,14 \\
\hline Relação Ca:P & 1,66 & 1,67 & 1,64 \\
\hline Lisina $^{2}$ & 1,78 & 1,75 & 1,82 \\
\hline Metionina $^{2}$ & 1,25 & 1,26 & 1,25 \\
\hline Arginina $^{2}$ & 2,09 & 2,11 & 2,14 \\
\hline Histidina $^{2}$ & 0,71 & 0,63 & 0,64 \\
\hline Isoleucina $^{2}$ & 1,04 & 1,07 & 1,11 \\
\hline Leucina $^{2}$ & 2,11 & 2,05 & 2,09 \\
\hline Fenilalanina $^{2}$ & 1,89 & 1,88 & 1,91 \\
\hline Treonina $^{2}$ & 1,11 & 1,11 & 1,14 \\
\hline Triptofano $^{2}$ & 0,26 & 0,20 & 0,20 \\
\hline Valina $^{2}$ & 1,42 & 1,49 & 1,54 \\
\hline
\end{tabular}

${ }^{1}$ Mistura vitaminas/minerais (por $\mathrm{kg}$ de produto): ác. fólico $300 \mathrm{mg}$; colina $100 \mathrm{~g}$; inositol $10 \mathrm{~g}$; niacina $9000 \mathrm{mg}$; ác. pantotênico 3000mg; biotina 0.1mg; Vit.A 1000000UI; Vit.B1 1500mg; Vit.B2 1500mg; Vit.B6 150mg; Vit.B12 2000mg; Vit.C 15g; Vit.D3 240000UI; Vit.E 10000mg; Vit.K3 400mg;cobre 1000mg; ferro $6000 \mathrm{mg}$; iodo $45 \mathrm{mg}$; manganês $8000 \mathrm{mg}$; selênio $60 \mathrm{mg}$; zinco $14 \mathrm{~g}$. ${ }^{2}$ Calculado com base na análise dos ingredientes; ${ }^{3}$ Carboidrato calculado: 100-(proteína+cinzas+gordura+fibra detergente neutro+umidade). ${ }^{4}$ Calculado a partir da fórmula: $($ Proteína $* 5,64 * 0,83)+\quad$ (gordura*9,44*0,88) + $($ Carboidrato*4,11*0,65)) * 10 (MEYER et al., 2004); CON= dieta controle, com base proteica composta de farinhas de origem animal; $\mathrm{CrIN}=$ inclusão de farelo de crambe in natura; $\mathrm{CrT}=$ inclusão de farelo de crambe tratado quimicamente.

550A); $\mathrm{pH}(6,82 \pm 0,14)$ (pHmetro Servylab, MPA 210-P); amônia $\left(0,11 \pm 0,09 \mathrm{mg} \mathrm{L}^{-1}\right)$ (VERDOUW et al., 1978); nitrito $\left(0,05 \pm 0,01 \mathrm{mg} \mathrm{L}^{-1}\right)$; alcalinidade $\left(20,78 \pm 5,32 \mathrm{mg} \mathrm{L}^{-1} \mathrm{CaCO}_{3}\right)$ e dureza $(43,56 \pm 10,28$ $\mathrm{mg} \mathrm{L}^{-1} \mathrm{CaCO}_{3}$ ) (BOYD \& TUCKER, 1992).

Antes de cada pesagem, os peixes jejuaram por 18 horas e, a seguir, foram anestesiados com eugenol $\left(20 \mu \mathrm{L}\right.$ de extrato puro $\mathrm{L}^{-1}$ água). Após, foram obtidos os dados de peso médio (g); comprimento total $(\mathrm{cm})$; ganho em peso diário $\left(\mathrm{g} \mathrm{dia}^{-1}\right)$; taxa de crescimento específico $\left(\% \mathrm{dia}^{-1}\right)$; ganho em peso relativo (\%); biomassa $(\mathrm{g})$; sobrevivência (\%) e conversão alimentar aparente. Após nove semanas de alimentação, foram capturados dois peixes por tanque (seis por tratamento) para coleta de sangue, retirado do vaso caudal com seringas heparinizadas. O sangue foi centrifugado para obtenção do plasma. Após, os animais foram anestesiados e abatidos por secção cervical para coleta do trato digestório e fígado. Todos os tecidos foram armazenados em freezer $\left(-18^{\circ} \mathrm{C}\right)$ até a realização das análises.

$\mathrm{O}$ trato digestório foi separado em estômago e intestino total. A protease ácida foi analisada no estômago e tripsina, quimotripsina e $\alpha$-amilase, determinadas no intestino, de acordo com os protocolos descritos em LAZZARI et al. (2010). Lipase intestinal foi quantificada conforme GAWLICKA et al. (2000). A proteína do estômago e intestino foi determinada pelo método de BRADFORD (1976).

O fígado foi fracionado em amostras de $50 \mathrm{mg}$ de tecido para análise de glicogênio, glicose, proteína total e amônia (metodologias descritas em PRETTO, 2013). As transaminases hepáticas - alanina aminotransferase (ALT) e aspartato aminotransferase (AST) e parâmetros bioquímicos plasmáticos (glicose, proteína total, triglicerídeos e colesterol) foram quantificados através de kits colorimétricos comerciais (Doles). Aminoácidos no fígado e plasma quantificados conforme SPIES (1957).

Os dados foram testados para normalidade, submetidos à análise de variância e a comparação dos tratamentos contendo o farelo de crambe com o controle foi realizada pelo teste de Dunnett. O teste $\mathrm{F}$ foi utilizado para comparar as médias entre os tratamentos contendo o farelo in natura, em relação ao farelo tratado. As análises estatísticas foram feitas através do software $\mathrm{SAS}^{\circledR}$, versão 8.2 (2001), considerando $\mathrm{P}<0,05$.

\section{RESULTADOS E DISCUSSÃO}

Os animais alimentados com as dietas CrIN e CrT não diferiram entre si e nem em relação ao controle para os parâmetros de crescimento avaliados (Tabela 3). Outro estudo conduzido com a espécie revelou melhor crescimento dos animais com a combinação de farinha de origem animal (de carne e ossos ou de peixe) com farelo de soja em relação à combinação com levedura ou dieta contendo farelo de soja como principal fonte proteica, 
Tabela 3 - Resposta de crescimento e atividade de enzimas digestivas em juvenis de jundiá alimentados com dieta a base de proteína de origem animal (controle) e dieta contendo farelo de crambe in natura ou tratado quimicamente após nove semanas experimentais.

\begin{tabular}{|c|c|c|c|}
\hline Variáveis $^{1}$ & $\mathrm{CON}$ & $\mathrm{CrIN}$ & $\mathrm{CrT}$ \\
\hline Peso inicial & $22,15 \pm 0,24$ & $22,19 \pm 0,14$ & $21,88 \pm 0,31$ \\
\hline Peso (g) final & $52,16 \pm 3,49$ & $46,91 \pm 3,00$ & $44,23 \pm 4,07$ \\
\hline $\mathrm{CT}(\mathrm{cm})$ final & $17,59 \pm 0,29$ & $16,89 \pm 0,33$ & $16,68 \pm 0,41$ \\
\hline GPD $\left(\mathrm{g} \mathrm{dia}^{-1}\right)$ & $0,48 \pm 0,05$ & $0,39 \pm 0,05$ & $0,35 \pm 0,07$ \\
\hline $\operatorname{TCE}\left(\% \mathrm{dia}^{-1}\right)$ & $1,35 \pm 0,10$ & $1,18 \pm 0,11$ & $1,10 \pm 0,15$ \\
\hline GPR (\%) & $135,4 \pm 14,8$ & $111,5 \pm 14,7$ & $102,5 \pm 19,3$ \\
\hline CAA & $3,03 \pm 0,63$ & $3,52 \pm 0,61$ & $4,00 \pm 0,72$ \\
\hline BM (g) & $662,8 \pm 59,6$ & $609,8 \pm 39,0$ & $574,9 \pm 52,9$ \\
\hline S (\%) & $98,0 \pm 1,9$ & $100 \pm 0,0$ & $100 \pm 0,0$ \\
\hline $\begin{array}{l}\text { Amilase }(\mu \mathrm{mol} \\
\text { glicose } \min ^{-1} \mathrm{mg} \\
\left.\text { proteína }^{-1}\right)\end{array}$ & $0,33 \pm 0,06$ & $0,40 \pm 0,05$ & $0,44 \pm 0,07$ \\
\hline $\begin{array}{l}\text { Lipase ( } \mu \text { g substrato } \\
\min ^{-1} \mathrm{mg} \mathrm{proteína}^{-1} \text { ) }\end{array}$ & $12,57 \pm 0,69$ & $12,68 \pm 1,22$ & $10,33 \pm 0,88$ \\
\hline $\begin{array}{l}\text { Protease ácida }(\mu \mathrm{g} \\
\text { tirosina } \min ^{-1} \mathrm{mg} \\
\left.\text { proteína }^{-1}\right)\end{array}$ & $119,9 \pm 7,6$ & $99,6 \pm 4,2^{\mathrm{a}}$ & $121,8 \pm 4,6^{*}$ \\
\hline $\begin{array}{l}\text { Tripsina ( } \mu \mathrm{mol} \\
\text { TAME } \min ^{-1} \mathrm{mg} \\
\left.\text { proteína }^{-1}\right)\end{array}$ & $8,63 \pm 0,64$ & $7,89 \pm 0,59$ & $7,28 \pm 0,39$ \\
\hline $\begin{array}{l}\text { Quimotripsina } \\
\left(\text { mmol BTEE } \min ^{-1}\right. \\
\left.\text { mg proteína }{ }^{-1}\right)\end{array}$ & $6,54 \pm 0,41$ & $6,54 \pm 0,35$ & $6,74 \pm 0,56$ \\
\hline
\end{tabular}

Valores expressos como média \pm erro padrão da média $(\mathrm{n}=3$ para desempenho e $n=6$ para enzimas digestivas). Letras indicam diferença para os tratamentos CrIN ou CrT em relação ao controle pelo teste de Dunnett $(\mathrm{P}<0,05)$. *Indica diferença entre a forma tratada e a forma in natura do farelo pelo teste $\mathrm{F}(p<0,05)$.

${ }^{1} \mathrm{CT}=$ comprimento total; $\mathrm{GPD}=$ ganho em peso diário; $\mathrm{TCE}=$ taxa de crescimento específico; $\mathrm{GPR}=$ ganho em peso relativo; $\mathrm{CAA}=$ conversão alimentar aparente; $\mathrm{BM}=$ biomassa; $\mathrm{S}=$ sobrevivência; $\mathrm{CON}=$ dieta controle, com base proteica composta de farinhas de origem animal; $\mathrm{CrIN}=$ inclusão de farelo de crambe in natura; $\mathrm{CrT}=$ inclusão de farelo de crambe tratado quimicamente.

devido à complementação de aminoácidos essenciais (LAZZARI et al., 2006). De acordo com OLIVEIRA FILHO \& FRACALOSSI (2006), o jundiá apresenta grande capacidade de digerir ingredientes proteicos, inclusive aqueles de origem vegetal. Essa característica pode ter contribuído para que as dietas com farelo de crambe, neste nível de substituição, proporcionassem crescimento semelhante ao controle. Em outras espécies, também foram encontrados resultados satisfatórios com a inclusão moderada de proteína vegetal na dieta. Para juvenis de Solea senegalensis, a substituição de $25 \%$ da farinha de peixe por uma mistura de proteínas vegetais proporcionou crescimento semelhante à dieta controle (farinha de peixe como principal fonte proteica) (CABRAL et al., 2011). Já, para exemplares de seabass (Lateolabrax japonicus), a inclusão de farelo de canola deve ser inferior a $20 \%$ para não afetar negativamente o crescimento (CHENG et al., 2010). Em dietas para o jundiá, assim como outras espécies, a proteína de origem animal pode ser substituída, em quantidade adequada, por proteína vegetal oriunda de um ou mais ingredientes e suplementando aminoácidos essenciais quando necessário. Neste estudo, a inclusão do farelo de crambe tratado quimicamente possivelmente confere à dieta CrT menor nível de antinutrientes. No entanto, essa diferença não foi demonstrada no crescimento de jundiás.

A capacidade digestiva de peixes está associada ao perfil e à concentração das enzimas produzidas. Fatores como a fonte, qualidade e a concentração de nutrientes na dieta podem modificar o padrão digestivo das espécies (RODILES et al., 2012). Redução na atividade de protease ácida ocorreu no tratamento CrIN, em relação ao CON e CrT após nove semanas de alimentação (Tabela 3). A inclusão do farelo in natura, com maior concentração de antinutrientes, pode estar associada à redução de protease. Em exemplares de L. japonicus, a inclusão de farelo de canola (50\%) na dieta reduziu a atividade de protease ácida, amilase e lipase, devido à presença de antinutrientes nesta fonte (CHENG et al., 2010). As enzimas intestinais avaliadas neste estudo não foram alteradas em jundiás dos tratamentos CrIN e CrT em relação ao CON (Tabela 3), mas indicadores mais sensíveis como os parâmetros metabólicos podem ser modificados.

Parâmetros bioquímicos relacionados ao metabolismo proteico e energético, avaliados em tecidos que refletem mudanças fisiológicas e nutricionais, como o plasma e o fígado, podem ser bons indicadores da resposta do animal a um determinado alimento. Os peixes que receberam o tratamento CrIN apresentaram menos colesterol plasmático do que os tratamentos CrT e CON. Glicose, proteína total, aminoácidos e triglicerídeos não foram alterados nos tratamentos avaliados (Tabela 4). A redução de colesterol plasmático em estudos com inclusão de proteína vegetal na dieta é atribuída ao efeito hipocolesterolêmico desses ingredientes, que 
Tabela 4 - Parâmetros bioquímicos em tecidos de juvenis de jundiá alimentados com dieta a base de proteína de origem animal (controle) e dieta contendo farelo de crambe in natura ou tratado quimicamente após nove semanas experimentais.

\begin{tabular}{|c|c|c|c|}
\hline Variáveis $^{1}$ & $\mathrm{CON}$ & $\mathrm{CrIN}$ & $\mathrm{CrT}$ \\
\hline GLI (mg dL $\left.{ }^{-1}\right)$ & $55,9 \pm 3,7$ & $47,8 \pm 1,8$ & $49,7 \pm 2,3$ \\
\hline PROT $\left(\mathrm{g} \mathrm{dL}^{-1}\right)$ & $3,10 \pm 0,07$ & $3,26 \pm 0,14$ & $3,09 \pm 0,04$ \\
\hline $\mathrm{AA}\left(\mathrm{mmoldL}^{-1}\right)$ & $4,38 \pm 0,04$ & $4,24 \pm 0,16$ & $4,26 \pm 0,20$ \\
\hline $\mathrm{TG}\left(\mathrm{mg} \mathrm{dL}^{-1}\right)$ & $429,6 \pm 56,9$ & $271,5 \pm 85,5$ & $272,6 \pm 39,4$ \\
\hline $\operatorname{COL}\left(\mathrm{mg} \mathrm{dL}^{-1}\right)$ & $172,1 \pm 8,1$ & $137,8 \pm 8,4^{\mathrm{a}}$ & $154,5 \pm 8,6$ \\
\hline GLG $\left(\mu \mathrm{mol}\right.$ glicose $\left.\mathrm{g}^{-1}\right)$ & $446,0 \pm 34,2$ & $332,8 \pm 30,8$ & $153,9 \pm 16,2^{a *}$ \\
\hline GLIH $\left(\mu \mathrm{mol}\right.$ glicose $\left.\mathrm{g}^{-1}\right)$ & $379,4 \pm 33,2$ & $423,4 \pm 16,5$ & $255,9 \pm 20,3^{a *}$ \\
\hline PROTH $\left(\mathrm{mg} \mathrm{g}^{-1}\right)$ & $49,9 \pm 4,2$ & $56,7 \pm 4,5$ & $64,3 \pm 2,5^{\mathrm{a}}$ \\
\hline $\mathrm{AM}\left(\mu \mathrm{mol} \mathrm{g} \mathrm{g}^{-1}\right)$ & $5,11 \pm 0,14$ & $5,77 \pm 0,32$ & $5,83 \pm 0,34$ \\
\hline ALT(UI mg $\left.{ }^{-1}\right)$ & $35,7 \pm 4,4$ & $29,1 \pm 5,0$ & $32,7 \pm 3,1$ \\
\hline AST (UI mg $\left.{ }^{-1}\right)$ & $687,9 \pm 107,2$ & $861,7 \pm 60,7$ & $1028,6 \pm 87,7^{\mathrm{a}}$ \\
\hline
\end{tabular}

Valores expressos como média \pm erro padrão da média $(n=6)$. Letras indicam diferença para os tratamentos CrIN ou CrT em relação ao controle pelo teste de Dunnett $(p<0,05)$. *Indica diferença entre a forma tratada e a forma in natura do farelo pelo teste $\mathrm{F}$ ( $\mathrm{P}<0,05)$. ${ }^{1} \mathrm{GLI}=$ glicose; $\mathrm{TG}=$ triglicerídeos; $\mathrm{COL}=$ colesterol; PROT=proteína total; AA=aminoácidos; GLG=glicogênio; GLIH=glicose hepática; PROTH=proteína hepática; $\mathrm{AM}=$ amônia; $\mathrm{ALT}=$ alanina aminotransferase; $\mathrm{AST}=$ aspartato aminotransferase. $\mathrm{CON}=$ dieta controle, com base proteica composta de farinhas de origem animal; $\mathrm{CrIN}=$ inclusão de farelo de crambe in natura; $\mathrm{CrT}=$ inclusão de farelo de crambe tratado quimicamente.

pode ser causado pelo aumento na excreção de sais biliares ou redução na absorção de colesterol. Além disso, também é sugerida a ação de antinutrientes como saponina, devido à sua afinidade pelo colesterol (DIAS et al., 2005).

Entre os efeitos metabólicos causados pelo ácido fítico na dieta de animais, tem sido relatada a redução de hormônios tireoidianos, inibição na atividade de amilase e digestão de amido e aumento nas reservas de glicogênio hepático e muscular (SZKUDELSKI, 2005). Para o tanino, foi observado in vitro um efeito inibitório sobre a atividade de amilase (FISH \& THOMPSON, 1991). Em relação aos parâmetros avaliados no fígado, neste estudo, ocorreu redução de glicogênio e glicose e aumento de proteína e AST nos peixes do tratamento $\mathrm{CrT}$ em comparação ao CON (Tabela 4). Esses dados poderiam concordar com os efeitos da redução de ácido fítico e taninos no farelo de crambe tratado e possivelmente a menor concentração destes antinutrientes no tratamento CrT. No entanto, essas alterações parecem mais relacionadas com a menor captação de energia neste tratamento pelos animais. Apesar da atividade das enzimas digestivas não estar alterada, a maior concentração de FDN, cinzas e menor conteúdo de carboidratos nesta dieta pode ter contribuído para a redução nas reservas energéticas. Aliada à menor concentração de glicogênio e glicose, o aumento de AST pode sinalizar uma situação de gliconeogênese, estratégia metabólica adotada pelo organismo para obtenção de energia. Entre os principais precursores gliconeogênicos, estão os aminoácidos. O aumento de proteína hepática nos peixes do tratamento CrT possivelmente está associado à maior concentração de AST, enzima relacionada à transaminação de aminoácidos no metabolismo intermediário e considerada indicativo de catabolismo proteico. FOURNIER et al. (2004) correlacionaram o aumento na atividade de aminotransferases com um decréscimo na eficiência proteica em juvenis de turbot (Psetta maxima) alimentados com dietas contendo farelos vegetais. Já, os animais alimentados com a forma in natura do farelo de crambe não apresentaram alterações nos parâmetros bioquímicos avaliados no fígado, sinalizando maior eficiência da dieta consumida e contribuição ao crescimento.

\section{CONCLUSÃO}

A semelhante resposta de desempenho nos animais alimentados com farelo de crambe in natura ou tratado pode significar que, no nível de inclusão utilizado, esse ingrediente não necessita de um processo prévio para remover antinutrientes. A inexistência de alterações bioquímicas no fígado dos peixes consumindo o farelo in natura também contribui para esse fato. Assim, trabalhos futuros devem avaliar o nível máximo de inclusão desta forma 
do farelo na dieta de jundiá. A inclusão do farelo tratado provocou várias alterações no metabolismo hepático de jundiás, sinalizando uma situação de carência energética no organismo e provavelmente deve ser incorporado em menor percentual na dieta.

\section{COMITÊ DE ÉTICA E BIOSSEGURANÇA}

Todos os procedimentos envolvendo animais foram conduzidos em concordância com a Comissão de Ética no Uso de Animais da Universidade Federal de Santa Maria (026/2011).

\section{REFERÊNCIAS}

BOYD, C.E.; TUCKER, C.S. Water quality and pond soil analysis for aquaculture. Alabama, USA:Alabama Agricultural Experiment Station, Auburn University, 1992. 183p.

BRADFORD, M.M.A. A rapid and sensitive method for the quantification of microgram quantities of protein utilizing the principle of protein-dye binding. Analytical Biochemistry, v.72, p.248-254, 1976. Disponível em: <http://www.ciens.ucv.ve:8080/generador/ sites/lab-bioq-gen/archivos/Bradford\%201976.pdf >. Acesso em: 18 mar. 2013

CABRAL, E.M. et al. Replacement of fish meal by increasing levels of plant protein blends in diets for Senegalese sole (Solea senegalensis) juveniles. Aquaculture, v.322-323, p.74-81, 2011 Disponível em: <http://ac.els-cdn.com/S0044848611007496/1s2.0-S0044848611007496-main.pdf? tid=2b4bd766-a82311 e2-a385-00000aab0f6b\&acdnat $=136628815736$ b5 519 ec af0717f116699d1ff7380a5>. Acesso em: 18 mar. 2013. doi:10.1016/j.aquaculture.2011.09.023.

CHENG, Z. et al. Effects of dietary canola meal on growth performance, digestion and metabolism of Japanese seabass, Lateolabrax japonicus. Aquaculture, v.305, p.102-108, 2010 Disponível em: <http://ac.els-cdn.com/S0044848610002036/1-s2.0-S004484861000203 6-main.pdf? tid=c70899bc-a825-11e2836e-00000aacb35d\&acdnat $=1366289278 \mathrm{f} 69 \mathrm{c} 697 \mathrm{e} 6 \mathrm{~b} \quad 7418 \mathrm{f} 9 \mathrm{ba}-$ e8252290f28f29>. Acesso em: 18 mar. 2013. doi:10.1016/j. aquaculture.2010.03.031.

DIAS, J. et al. Dietary protein source affects lipid metabolism in the European seabass (Dicentrarchus labrax). Comparative Biochemistry and Physiology A, v.142, p.19-31, 2005. Disponível em: <http://ac.els-cdn.com/S1095643305002515/1s2.0-S1095643305002515-main.pdf?_tid=6380eb78-a826-11e29fb7-00000aab0f01\&acdnat $=136628954057$ babde $935 \mathrm{cca}-$ 508f50f5d4bd62d5568> . Acesso em: 18 mar. 2013. doi:10.1016/j. cbpb.2005.07.005.

FISH, B.C; THOMPSON, L.U. Lectin-tannin interactions and their influence on pancreatic amylase activity and starch digestibility. Journal of Agricultural and Food Chemistry, v.39, p.727731, 1991. Disponível em: <http://pubs.acs.org/doi/pdf/10.1021/ jf00004a021>. Acesso em: 03 out. 2013.

FOURNIER, V. et al. Incorporation of a mixture of plant feedstuffs as substitute for fish meal in diets of juvenile turbot (Psetta maxima). Aquaculture, v.236, p.451-465, 2004. Disponível em: <http://ac.els-cdn.com/S004484860400081X/1s2.0-S004484860400081X-main.pdf?tid=98 10942 -cedb-11e28d81-00000aab0f27\&acdnat $=1370545513 \_18 \mathrm{a} 597243 \mathrm{c} 07073$ 441669fe 5f71d69a3>. Acesso em: 03 jun. 2013. doi:10.1016/j. aquaculture.2004.01.035.

GAWLICKA, A. et al. Activity of digestive enzymes in yolk-sac larvae of Atlantic halibut (Hippoglossus hippoglossus): indication of readiness for first feeding. Aquaculture, v.184, p.303-314, 2000. Disponível em: <http://ac.els-cdn.com/S0044848699003221/1s2.0-S $0044848699003221-$ main.pdf?_tid=aa $87 f 5 c 2$ d2c7-11e2-b91a-00000aab0f27\&acdnat $=1370976757$ e b7bbc52622af3f0f74bc26f4703a00>. Acesso em: 11 jun. 2013.

KROGDAHL, A. et al. Important antinutrients in plant feedstuffs for aquaculture: an update on recent findings regarding responses in salmonids. Aquaculture Research, v.41, p.333-344, 2010. Disponível em: <http://onlinelibrary.wiley.com/doi/10.1111 /j.1365-2109.2009.024 26.x/ pdf>. Acesso em: 11 jun. 2013. doi: 10.1111/j.1365-2109.2009.02426.x.

LAZZARI, R. et al. Diferentes fontes proteicas para a alimentação do jundiá (Rhamdia quelen). Ciência Rural, v.36, n.1, p.240246, 2006. Disponível em: <http://www.scielo.br/pdf /cr/v36n1/ a37v36n1.pdf>. Acesso em: 03 jun. 2013. doi:10.1590/S010384782006000100037.

LAZZARI, R. et al. Protein sources and digestive enzyme activities in jundiá (Rhamdia quelen). Scientia Agricola, v.67, p.259-266, 2010. Disponível em: <http://www.scielo.br/pdf/s a/ v67n3/a02v67n3.pdf>. Acesso em: 03 jun. 2013. doi:10.1590/ S010 3-90162010000300002.

MEYER, G. et al. A importância da quantidade de energia na ração de peixes. Panorama da Aquicultura, v.14, p.53-57, 2004. Disponível em: <http://www.panoramadaaquicultura.com.b r/ paginas/paginas $/ 09$ _validate/index.asp? Edicao $=83>$. Acesso em: 11 jun. 2013.

OLIVEIRA FILHO, P.R.C.; FRACALOSSI, D.M. Coeficientes de digestibilidade aparente de ingredientes para juvenis de jundiá. Revista Brasileira de Zootecnia, v.35, n.4, p.1581-1587, 2006. Disponível em: <http://www.scielo.br/pdf/rbz/v35n4s0/ a02v354s.pdf $>$. Acesso em: 11 jun. 2013. doi: 10.1590/S151635982006000600002 .

PITOL, C. et al. Tecnologia e produção: crambe 2010. Maracaju:Fundação MS, 2010. 60p.

PRETTO, A. Detoxificação de farelos de crambe e tungue e avaliação na resposta nutricional do jundiá Rhamdia quelen. 2013. 175f. Tese (Doutorado em Zootecnia) - Curso de Pósgraduação em Zootecnia, Universidade Federal de Santa Maria, RS.

RODILES, A. et al. Effect of dietary protein level and source on digestive proteolytic enzyme activity in juvenile Senegalese sole Solea senegalensis. Aquaculture International, v.20, p.10531070, 2012. Disponível em: <http://link.springer.com/content/ pdf/10.1007\%2Fs10499-012-9508-6.pdf>. Acesso em: 11 jun. 2013. doi:10.1007/s10499-012-95086.

SALHI, M. et al. Growth, feed utilization and body composition of black catfish, Rhamdia quelen, fry fed diets containing different protein and energy levels. Aquaculture, v.231, p.435-444, 2004. Disponível em: <http://ac.els-cdn.com/S0044848603005544/1-s2.0-S004484 8603005544-main.pdf? tid=85729414-d2cb-11e2a89d-00000aacb361\&acdnat=1370978413 66f273bae59c18461ea5c085c5494f12>. Acesso em: 11 jun. 2013. 
SPIES, J.R. Colorimetric procedures for amino acids. Methods in Enzymology, v.3, p.467-477, 1957. Disponível em: <http:// www.sciencedirect.com/science/article/pii/S0076687957034175>. Acesso em: 11 jun. 2013. doi: 10.1016/S0076-6879(57)03417-5.

SAS INSTITUTE. SAS/STAT User's guide. Version 8.2. Cary, NC, USA: Statistical Analysis System Institute, 2001. 943p.

SZKUDELSKI, T. Phytic acid-induced metabolic changes in the rat. Journal of Animal Physiology and Animal Nutrition, v.89, p.397-402, 2005. Disponível em: <http://onlinelibrary.wiley.com/ doi/10.1111/j.1439-0396.2005.00532.x/pdf>. Acesso em: 03 out. 2013. doi: 10.1111/j.1439-0396.2005.00532.x.
VERDOUW, H. et al. Ammonia determinations based on indophenol formation with sodium salicylate. Water Research, v.12, p.399-402, 1978.Disponívelem:<http://ac.els-cdn.com/0043135478901070/1s2.0-0043135478901070-main.pdf? tid=7c4fcfee-d2cd11 e2-bf0e-00000aacb361\&acdnat $=1370979257$ e9c2f67a83c160480a29a351af793466>. Acesso em: 11 jun. 20 13. doi: 10.1016/0043-1354(78)90107-0.

YANG, Y. et al. Effect of replacement of dietary fish meal by meat and bone meal and poultry by-product meal on growth and feed utilization of gibel carp, Carassius auratus gibelio. Aquaculture Nutrition, v.10, p.289-294, 2004. Disponível em: <http://onlinelibrary.wiley.com/doi/10.1111/j.1365-2095.2004.00301.x/pdf>. Acesso em: 11 jun. 2013. 